
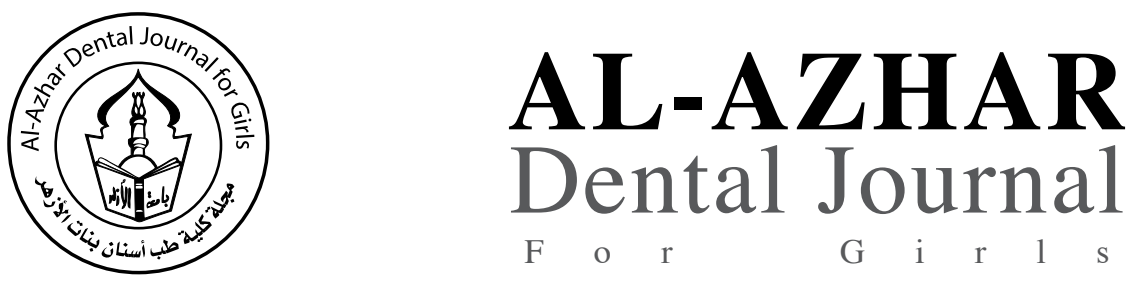

The Official Publication of The Faculty of Dental Medicine For Girls, Al-Azhar University Cairo, Egypt.

ADJ-for Grils, Vol. 3, No. 1, January (2016) — PP. 61:67

\title{
Effect of Abutment Total Occlusal Convergence and Cement Type on Retention of Cement Retained Implant-Supported Restorations
}

\author{
Abeer H. EIHiatmy ${ }^{(1)}$, Osama S. AbdelGhany ${ }^{(2)}$ and Rania A. Amin ${ }^{(2)}$
}

Codex : 09/1601

dentaljournal.forgirls@yahoo.com

\section{KEYWORDS}

CAD/CAM abutments, cement retained implant, RMGI, self adhesive resin cements

\begin{abstract}
The purpose of this study was to evaluate the effect of abutment total occlusal convergence (TOC), and cement type on the uniaxial tensile resistance to dislodgment of cement-retained, implant-supported metal copings. Six titanium implant abutmnets were constructed using CAD-CAM technology. Two abutments have TOC $6^{\circ}$, Two abutments have TOC $8^{\circ}$, and Two abutments have TOC $12^{\circ}$. Identical copings were cast to fit each abutment with a loop incorporated that was engaged by the testing unit. The copings were cemented using either a resin-modified glass ionomer (RMGI) (Rely ${ }^{\mathrm{TM}}$ X U 200 Automix) or self adhesive resin cement that contained a 10 Methacryloyloxydecyl dihydrogen phosphate (MDP) monomer (Multilink® N). Each of the experimental groups had a unique combination of abutment TOC, and cement. Specimens were aged using a thermocycling unit with water between 5 and 55 degrees Celsius with 15 seconds in each bath and a 5 seconds dwell time, for 540 cycles. A universal testing machine was used to test uniaxial tensile strength. Cement was cleaned using thermal, mechanical, and physical methods, and surface finish was reestablished. This procedure was repeated to obtain different measurements for each group. Surface area for each abutment was calculated and used for the calculation of the tensile strength. One way ANOVA followed by pair-wise Newman-Keuls post-hoc tests were performed to detect significance between subgroups. Pair-wise student t-test was performed to detect interaction between variables of significant effect.P values $\leq 0.05$ are considered to be statistically significant in all tests. Regardless of the cement type, totally it was found that Group $A$ recorded the highest retentive force mean values followed by Group B while Group $\boldsymbol{C}$ recorded the lowest retentive force mean values. The difference between all groups was statistically significant $(\mathrm{p}<0.05)$. Pairwise Newman-Keuls post-hoc tests showed that the difference between Group $A$ and Group B was statistically non-significant ( $\mathrm{p}>0.05$ ). Irrespective of convergence groups, totally it was found that Multilink $\boldsymbol{N}$ group recorded statistically significant $(\mathrm{p}<0.05)$ higher retentive force mean values than Rely X U200 one.
\end{abstract}

1. B.D.S Faculty of Oral and Dental Surgery, Tanta University (2008).

2. Assistant Professor Crown and Bridge Department, Faculty of Dental Medicine for Girls, AL-Azhar University. 


\section{INTRODUCTION}

Implant therapy is a well-documented treatment for replacing missing teeth. The implant-supported prostheses are attached to implant abutments either by cementation, or by retaining screws ${ }^{(1)}$. Because of the advantages of cement-retained implant-supported restorations, such as passive fit, reduced cost, ease of fabrication, superior esthetic, fewer components, and uncomplicated laboratory technique, these restorations have gain popularity compare to screw-retained restorations..$^{(1)}$ Even though cement wash outs occur in cement-retained restorations, they do have high clinical success rates. ${ }^{(1)}$

Retrievability may be a critical aspect of implantsupported restorations because of problems such as loosening or fracture of the abutment screws, mechanical failures, treatment of peri-implant tissues, and evaluation of ailing implants mobility. ${ }^{(2,3)}$ Although using provisional cements are considered to achieve retrievability of implant-supported prostheses, retrievability of screw-retained prostheses is more secure than cement-retained ones. ${ }^{(2,3)}$

Retention of implant-supported restorations plays an important role in success of the treatment. Uncemented restorations may cause problems such as inhalation of the restorations, increased bone loss around the implant, prosthesis failure breakage, trauma to antagonistic teeth, food impaction, accumulation of microorganisms resulting in bad odor and soft tissue response. Extra practitioner time and patient embarrassment have also been noted. ${ }^{(3,4)}$

On the other hand, luting agents that are too retentive may damage the osseointegration of the implant during removal of the restoration. ${ }^{(3,4)}$

Behavior of permanent and provisional luting agents in cementation of implant-supported prostheses differs from cementation on natural teeth. In particular, water-based cements such as zinc phosphate, zinc polycarboxylate, and glass ionomer, have shown a wide variety of retentive values, which can sometimes be unpredictable..$^{(3,5)}$
Some authors suggested the use of permanent and provisional cements for luting single-unit and multi-unit implant-supported restorations, respectively. ${ }^{(6)}$

Provisional cements have been recommended for restorations that may require intervention, whereas, more retentive cements, such as resin cement, are more appropriate when future retrievably is not necessary. ${ }^{(4-7)}$

The use of different cements, protocols, and implant systems may alter the retentive strength of implant-supported restorations, in addition, different aging processes, such as thermal cycling and mechanical loading, as well as different pretreatment techniques can also affect the retentive strength. ${ }^{(4,6,7)}$

Several factors influence the retention of cemented implant prostheses, including convergence angle, height, and surface roughness of the abutment. . $^{(4,6,7)}$

\section{MATERIALS AND METHODS}

One implant system was used with tapered screw vent implant analogue with the following dimensions $13 \mathrm{~mm}$ length, $4.8 \mathrm{~mm}$ upper diameter, 4.4 $\mathrm{mm}$ apex diameter with 7 degrees taper and $\mathrm{CAD} /$ CAM manufactured titanium abutments with $6 \mathrm{~mm}$ length, $3.5 \mathrm{~mm}$ platform diameter and 0.5 chamfer finishing line.

Two cements were used; Multilink ${ }^{\circledR} \mathrm{N}$ self adhesive cement with light curing option, and Rely $X^{\mathrm{TM}} \mathrm{U} 200$ Auto-mix dual-curing, self adhesive resin modified glass ionomer cement supplied in an auto-mix syringe.

The cad/cam abutments were constructed from a Grade 5 titanium alloy blocks using a 4-axis desktop milling machine.

Implant analogues were seated in a system three epoxy resin blocks simulates bone then the customized abutments were screwed into it with a tapered Hex tool. 
Twenty Metal Copings were manufactured from a Non - precious (Nickel- Chromium) dental casting alloy for each group.

The samples of each group were divided into two sub groups according to the type of cement used. The samples of sub group (1) cemented using Multilink N self-adhesive Cement. The samples of sub group (2) cemented using RelyX ${ }^{\mathrm{TM}} \mathrm{U} 200$ resin modified glass ionomer cement.

The assemblies were stored in $100 \%$ humidity and $37^{\circ}$ Celsius for 24 hours and then subjected to thermal cycling in water bath at $50-55$ degree Celsius. After thermo cycling the copings were subjected to uni-axial tensile strength testing using universal testing machine using a load cell of $5 \mathrm{KN}$.

Data were recorded using computer software (Nexygen -MT Lloyd Instruments).

The residual cement was removed from the abutments surfaces by spoon excavator and then cleaned with a plastic explorer. The abutments were immersed in ultrasonic cleaner containing cement removal agent or 30 minutes and 15 minutes respectively according to the instructions. The same abutment complex was used with new copings within the same cement group to eliminate the possibility of surface contaminations from different cements and avoid interactions between material residuals.

Sixteen times magnification was used to ensure the abutments surfaces were free of residual cement by using a stereomicroscope. Then abutments were ready for re-cementation with another new metal coping.

\section{RESULTS}

Data analysis was performed in several steps. Initially, descriptive statistics for each group results.

Two-factor analysis of variance ANOVA test of significance comparing variables (Convergence group and cement) affecting mean values.

One way ANOVA followed by pair-wise Newman-Keuls post-hoc tests were performed to detect significance between subgroups. Pair-wise student t-test was performed to detect interaction between variables of significant effect.

\section{Statistical Analysis related to TOC Retentive Forces as function of cement:}

It was found that for Group A (6o) the mean \pm SD values were $(383.145 \pm 47.681 \mathrm{~N})$ with Multilink N cement and $(289.978 \pm 47.086 \mathrm{~N})$ with Rely X U 200 cement.

While for Group B $(8 \boldsymbol{8})$ the mean \pm SD values were $(299.619 \pm 13.354 \mathrm{~N})$ with Multilink N cement and $(333.517 \pm 8.660 \mathrm{~N})$ with RelyX ${ }^{\mathrm{TM}} \mathrm{U} 200$ cement.

Group $C$ (12o) the mean \pm SD values were $(297.111 \pm 50.124 \mathrm{~N})$ with Multilink N cement and $(269.487 \pm 34.703 \mathrm{~N})$ with Rely X U200 cement.

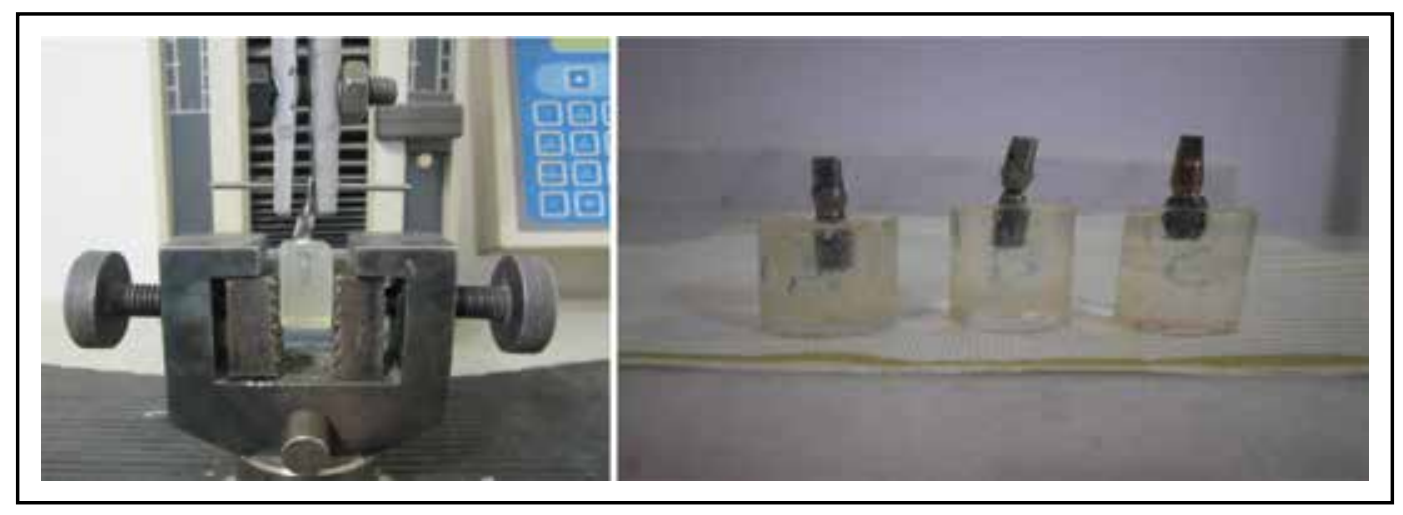




\section{Analysis of variance(ANOVA) test of significance:}

Table (1) two way analysis of variance ANOVA test of significance comparing variables affecting retentive force results

\begin{tabular}{|c|c|c|c|c|c|}
\hline Source of Variation & $D f$ & $S S$ & $M S$ & $F$ & $P$ value \\
\hline Convergence groups & 2 & 28955.65 & 14477.83 & 6.1376 & $0.003 *$ \\
\hline Cement & 1 & 12584.3 & 12584.3 & 5.3349 & $0.024 *$ \\
\hline Interaction & 2 & 40376.49 & 20188.25 & 8.5585 & $0.001 *$ \\
\hline
\end{tabular}

\section{Influence of total occlusal Convergence groups:}

Regardless of the cement type, totally it was found that Group $\boldsymbol{A}$ recorded the highest retentive force mean values followed by Group B while Group $\boldsymbol{C}$ recorded the lowest retentive force mean values. The difference between all groups was statistically significant $(\mathrm{p}<0.05)$. Pair-wise NewmanKeuls post-hoc tests showed that the difference between Group $\boldsymbol{A}$ andGroup $\boldsymbol{B}$ was statistically nonsignificant $(\mathrm{p}>0.05)$.

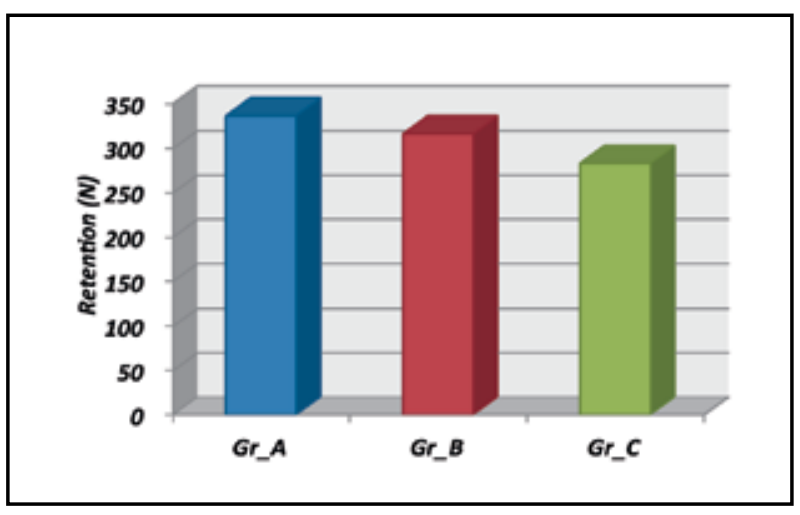

Fig. (1) A column chart comparing between total retentive force mean values as function of convergence groups

\section{Influence of cement type:}

Irrespective of convergence groups, totally it was found that Multilink $N$ group recorded statistically significant $(\mathrm{p}<0.05)$ higher retentive force mean values than Rely $X \boldsymbol{U} \mathbf{2 0 0}$ one.

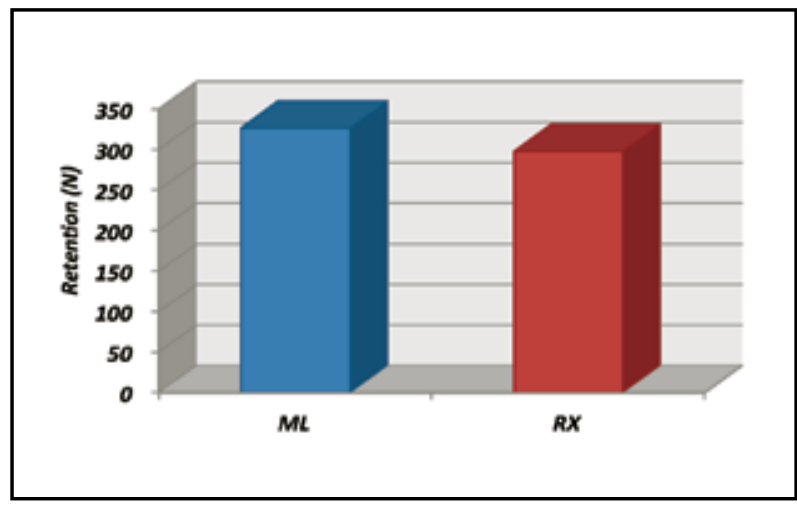

Fig. (2) A column chart comparing between total retentive force mean values as function of cement

\section{DISCUSSION}

The cemented implant supported crowns were used because of its advantages over the screw retained one. They have the advantages of simplicity, hermetic sealing of the abutment-crown interface, favorable aesthetics and crown contour, and a single interface between abutment and implant. ${ }^{(8,9)}$

However, universal applicability of the technique is restricted by its most prominent disadvantage, which is the loss in ease of retrievability of the cemented superstructure. Retrievability is highly desirable for cleaning and it facilitates evaluation for mobility ailing implants. ${ }^{(2,9,10)}$ However, the use of such cemented superstructure on an implant might not permit its removal for future maintenance. ${ }^{(11,12)}$

The convergence of the abutments used in the cemented implant system has a great role in retention of the restoration. In this study a total occlusal convergence of $6^{\circ}, 8^{\circ}$ and $12^{\circ}$ were used respectively. Abutments were fabricated using a CAD/CAM system. In comparison to cast abutments, there is no need for complicated and time-consuming titanium casting and post- casting manipulation that may produce inaccuracies; hence, the $\mathrm{CAD} / \mathrm{CAM}$ abutment fit may be more precise. Moreover, the $\mathrm{CAD} / \mathrm{CAM}$ custom abutments have better physical properties since the material is processed from a homogenous mass under more controlled conditions, with no need for abutment inventory. ${ }^{(13)}$ 
In practice, ideal axial wall convergence is rarely obtained, and lack of retention is a common cause of fixed prosthesis failure. In this study, the use of a smooth surface and angled titanium abutment may have increase the mechanical retention of the cemented copings. The results would likely be different if the implants were not positioned perpendicular to the horizontal crestal plane and if the study was repeated with other implant systems. ${ }^{(1)}$

In the current study, the copings were cemented on the same abutments multiple times. Reduced retention may occur if a coping is cemented over an abutment again if any cement remains on the abutment. ${ }^{(5)}$ Although care was taken to remove all cement from the abutment and the casting after tensile loading, it is possible that the fit of the castings were not similar.

In implant dentistry, careful consideration of the choice of the cement type include reference to abutment and crown specifications, opposing surfaces characteristics, desired retention, individual properties of preferred cement and ease of excess cement removal. ${ }^{(14,15)}$ The dental cements used for cement retained implant supported restorations may present different effects when compared with those used on teeth. ${ }^{(16)}$

In considering implant abutment- retained crowns. The ideal cement should be strong enough to retain the crown indefinitely, yet weak enough to allow the clinician to retrieve it if necessary. ${ }^{(17)}$

Type of luting agent and variations in its viscosity also affected the retentiveness of definitive restorations. ${ }^{(1,18,20,21)}$ The most common technical complications of cement-retained implant supported fixed restorations were loss of retention (16.8\%), particularly when temporary cements and short abutments were used. ${ }^{(22)}$

The majority of cements used in implant dentistry at present have been designed for use with crowns lutes to natural teeth. In cementing crowns to implant abutments, luting agents are required to act in a different manner to oppose two metallic surfaces whereas with natural teeth one surface normally consists of enamel, dentine or restorative material. Different types of cements provide different levels of crown retention. ${ }^{(22,23)}$

Logically, no single retrievable cement will suffice for all clinical situations. The type of cement used is also an important consideration because it affects the retention characteristics of the restoration. It may be desirable to use a type of cement that allows the restoration to be retrieved, so that superstructure can temporarily be cemented to evaluate the loading of implant occlusion, tissue response and screw loosening. Although the rationale for temporary cementation was based on the idea of providing ease in retrievability of the prosthesis, quick washout of such cements in the oral cavity possibly poses risk to periodontal health when the maintenance schedule cannot be kept properly. ${ }^{(24)}$

In this study, permanent cements were used, Resin Modified Glass Ionomer cement (Rely $\mathrm{X}^{\mathrm{TM}}$ U200) and dual cure self-adhesive Resin Cement (Multilink N) were used with customized titanium implant abutments and metal casted copings.

Multi-link N self-adhesive resin cement was used in this study; it is a self-curing, self-etching luting composite system, which can be used for nearly all the typical clinical cementation applications. Moreover, it also offers the possibility of final light-curing. In the Multilink / Multilink Primer system, the material sets quickly and reliably and excess cement can be easily removed.

Together with the Multilink Primer, very high bonding values are achieved after only a short time. In investigations on the marginal quality, Multilink $\mathrm{N}$ also showed outstanding results. The silane methacrylate group establishes a bond to silicate ceramic materials, the phosphoric acid methacrylate group is responsible for bonding to zirconium oxide, aluminium oxide and base metals and the disulfide methacrylate group creates a bond to gold and precious metals and the corresponding alloys. 
Also, it is radio-opaque cement with $350 \%$ opacity compared with aluminium.

Rely $\mathrm{X}^{\mathrm{TM}} \mathrm{U} 200$ is resin modified glass ionomer cement, this cement adheres to metal by chelating metallic ions, but the retentive strength may be weakened by early water contact. ${ }^{(25)}$

In this study higher bond strength was recorded for Group A $\left(6^{\circ}\right)$ with Multilink N Resin Cement, while the lowest bond strength was recorded for Group C $\left(12^{\circ}\right)$ with Rely X ${ }^{\mathrm{TM}}$ U200 Resin Modified Glass Ionomer Cement .

A combination of Resin cements and titanium alloy was reported to have higher bond strength compared to other alloys. ${ }^{(12)}$

In this study the samples were stored in $37 \mathrm{c}$ incubator for 24 hours after cementation and then thermo cycled for 500 cycles (5-55) with $30 \mathrm{~s}$ dwell time. Long-term water storage and thermal cycling are the conditions most often used to test the durability of cements bonds. However long-term water storage was combined with thermal cycling at regular intervals to test the durability of the bonds. ${ }^{(18)}$ Some cement, particularly the glass ionomers, have been found to be especially sensitive to early moisture. ${ }^{(11,14)}$

In this study, base metal alloys were used for the cast restorations. Base metal alloys are less expensive than noble base alloys, so they are preferred for most cast restorations. Reduced retention may occur if a crown is cemented over an abutment again if any cement remains on the abutmen. ${ }^{(5)}$ Although care was taken to remove all cement from the abutment and the casting after tensile loading, it is possible that the fit of the castings was not as good as with the first group.

Uniaxial tensile testing was employed in the current study as it permitted comparison with previous investigations of a similar nature. ${ }^{(27)}$ A purely tensile test may not represent the clinical stresses where other non-axial forces may contribute to crown de-cementation. ${ }^{(28)}$
The range of retention values and standard deviations in the current study were high. This has been noted and discussed in other studies of this nature and may be related to difficulties in study design including small sample sizes, construction and testing variations and the relative unpredictability and sensitivity of cements..$^{(7,27,29)}$

\section{CONCLUSIONS}

\section{Within limitations of this In Vitro study:}

1. Both Total occlusal convergence and Cement type have significant effect on retention of cement retained implant supported restorations.

2. Increase of Total occlusal convergence of implant abutments decreased the retention of the cemented crowns.

3. Resin Cement (Multilink $\mathrm{N}^{\circledR}$ ) enhanced the retention of the cemented crowns compared with Resin Modified Glass Ionomer Cement (Rely X ${ }^{\mathrm{TN}}$ U200).

\section{REFERENCES}

1. Bernal G, Okamura M, Munoz CA. The effects of abutment taper, length and cement type on resistance to dislodgement of cement-retained, implant-supported restorations. J Prosthodont; 12: 111-115, 2003.

2. Hebel KS, Gajjar RC. Cement-retained versus screwretained implant restorations: Achieving optimal occlusion and esthetics in implant dentistry. J Prosthet Dent;77: 2835, 1997.

3. Misch CE. Principles of cement-retained fixed implant prosthodontics. In: Misch CE, editor. Dental Implant Prosthetics. St.louis: Elsevier Mosby;pp. 414-51, 2005.

4. Chee W, Jivraj S: Screw versus cemented implant supported restorations. Br Dent J; 201: 501-507, 2006.

5. Squier RS, Agar JR, Duncan JP, Taylor TD. Retentiveness of dental cements used with metallic implant components. Int J Oral Maxillofac Implants;16:793-8, 2001.

6. Bresciano M, Schierano G, Manzella C, et al. Retention of luting agents on implant abutments of different height and taper. Clin Oral Implants Res;16: 594- 598, 2005. 
7. Michalakis KX, Hirayama H, Garefis PD. Cement-retained versus screw-retained implant restorations: A critical review. Int J Oral Maxillofac Implants;18:719-28, 2003.

8. Chee W, Felton DA, Johnson PF and Sullivan DY: Cemented versus screw-retained implant prostheses. Which is better? Int J Oral Maxillofac Implants; 14: 137$141,1999$.

9. Vigolo P, Givani A, Majzoub Z, Cordioli G. Cemented versus screw-retained implant supported single tooth crowns: a4-years prospective clinical study. Int J Oral Maxillofac Implants;19:260-265, 2004.

10. Scheller H, Urgell JP, Kultje C,Klineberg I, Goldberg PV, Stevenson- moore P, Alonso JM, Schaller M,Corria RM,Engquist B,Toreskog S, Kastenbaum F and Smith CR. A5-year multicenter study on implant-supported single crown restorations. Int $\mathrm{J}$ Oral Maxillofac Implants, 13:212-218,1998.

11. Sheets JL, Wilcox C and Wilwerding C: Cement selection for cement retained crown technique with dental implants. J Prosthodont; 17: 92-96, 2008.

12. Chan DCN, Wilson AH, Barbe P, Cronin RJ, Chung C and Chung K. Effect of preparation convergence on retention and seating discrepancy of complete veneer crowns. J Oral Rehabil.32:58-64, 2005.

13. GrossmannY, Pasciuta M, Finger IM. A novel technique using a coded healing abutment for the fabrication of a CAD/CAM titanium abutment for an implant supported restoration. The journal of prosthetic dentistry; 95:258$261,2006$.

14. Breeding LC, Dixon DL and Bogacki MT: Use of luting agents with an implant system: Part I. J Prosthet Dent; 68: 737-741, 1992.

15. Gorodovsky S, Zidan O. Retentive strength, disintegration, and marginal quality of luting cements. J Prosthet Dent;68:269-274, 1992

16. Kerby RE, McGlumphy EA, Holloway JA. Some physical properties of implant abutment luting cements. Int J Prosthodont;5:321-325, 1992.

17. Ramp MH, Dixon DL and Ramp LC: Tensile bond strengths of provisional luting agents used with an implant system. J Prosthet Dent; 81: 510-514, 1999.
18. GaRey DJ, Tjan AHL and James RA: Effects of thermal cycling, load cycling, and blood contamination on cemented implant abutments. J Prosthet Dent; 71:124-132, 1994.

19. Kim Y, Yamashita J, Shotwell JL, Chong K-H, Wang H-L. The comparison of provisional luting agents and abutment surface roughness on the retention of provisional implantsupported crowns. J Prosthet Dent;95:450-455, 2006.

20. Emms M, Tredwin CJ, Setchell DJ, Moles DR. The effects of abutment wall height, platform size,and screw access channel filling method on resistance to dislodgement of cement -retained implant supported restorations. J Prosthodont;16:3-9, 2007.

21. Dudley JE, Richards LC and Abbott JR: Retention of cast crown copings cemented to implant abutments. Aust Dent J; 53: 332-339, 2008.

22. Maeyama H, Sawase T and Jimbo R: Retentive strength of metal copings on prefabricated abutments with five different cements. Clin Implant Dent Relat Res.; 7:229-34, 2005.

23. Wahl C, Mantovani FG and Barbosa RB: Assessment of the tensile strength of hexagonal abutments using different cementing agents: Braz Oral Res; 22: 299-304, 2008.

24. Akca K, Iplikcioglu H, Cehreli MC. Comparison of uniaxial resistance forces of cements used with implantsupported crowns. Int J Oral Maxillofac Implants;17:536-542, 2002.

25. Mansour A, Ercoli C and Graser G: Comparative evaluation of casting retention using the ITI solid abutment with six cements. Clin Oral Impl Res; 13: 343-348, 2002.

26. Burke FJ, Fleming GI, Nathanson D, Marquis PM. Are adhesive technologies needed to support ceramics? An assessment of the current evidence. J Adhes Dent; 4:7-22, 2002.

27. Nazarian A: Easier implant restoration: CAD/CAM generated implant abutments: Contemporary Esthetics; 2: 44-48, 2007.

28. Tomson PLM, Butterworth CJ and Walmsley AD: Management of peri-implant bone loss using guided bone regeneration: a clinical report. J Prosthet Dent; 92:12-16, 2004.

29. Dodge WW, Weed RM and Baez RJ: The effect of convergence angle on retention and resistance form. Quintessence Int; 16: 191-194, 1985. 